This PDF is a selection from a published volume from the National Bureau of Economic Research

Volume Title: Labor in the New Economy

Volume Author/Editor: Katharine G. Abraham, James R. Spletzer, and Michael Harper, editors

Volume Publisher: University of Chicago Press

Volume ISBN: 978-0-226-00143-2; 0-226-00143-1

Volume URL: http://www.nber.org/books/abra08-1

Conference Date: November 16-17, 2007

Publication Date: October 2010

Chapter Title: Emerging Labor Market Trends and Workplace Safety and Health Chapter Author: Nicole Nestoriak, John Ruser

Chapter URL: http://www.nber.org/chapters/c10832

Chapter pages in book: (425 - 453) 


\title{
Emerging Labor Market Trends and Workplace Safety and Health
}

\author{
Nicole Nestoriak and John Ruser
}

\subsection{Introduction}

Emerging labor market trends will impact occupational safety and health (OSH). Certain labor market trends, such as the decline in goods-producing industries, affect safety and health outcomes in known ways, and their impact can be predicted. Other trends, such as the use of contract workers and new workplace practices, have the potential to affect not only rates of injury and illness but also OSH monitoring. This chapter addresses the impact of labor market trends on OSH outcomes and surveillance.

The aging of the workforce will affect the types and severity of injuries and illnesses received. The growth in service-producing industries and the decline in traditional goods-producing industries also have implications for the composition and overall number of OSH cases. While the shift to service industries has been accompanied by a decline in the aggregate occupational injury and illness rate, some service industries have seen rate increases. The shift has also been accompanied by greater exposure to risk by some groups of workers, such as women, who have tended to work in safer jobs.

Beyond these basic worker characteristics, there are a host of other labor market trends that are likely to have an impact on workplace injuries, illnesses, and fatalities that are not easily measurable. The Employment Services industry, which includes Temporary Help Services and Professional Employer Organizations, is predicted to be a large source of employment

Nicole Nestoriak is a research economist in Compensation Research and Program Development at the Bureau of Labor Statistics. John Ruser is Assistant Commissioner for Safety and Health Statistics at the Bureau of Labor Statistics.

The views expressed are those of the authors and do not necessarily reflect the views or policies of the BLS or any other agency of the U.S. Department of Labor. 
growth over the next decade. For workers in these industries and for contract workers more generally, the separation of where an employee works from who he or she is employed by can lead to confusion both in workplace practices intended to improve safety and health and also in OSH reporting. Similarly, employers with workers who work at home are not liable for maintaining the safety and health of those home work sites. Finally, new workplace practices such as Total Quality Management have been introduced to improve quality but may also have unintended negative consequences for worker safety and health.

In the numerical analysis, this chapter focuses on the impact on workplace safety of future changes in the age, gender, industrial, and occupational composition of employment over the next decade. The chapter also speculates about the impact of other labor market trends on future occupational injuries and illnesses. It is important to observe that there are factors outside of these labor market trends that have contributed to a large decline in injury and illness rates in the United States since the early 1990s. Specifically, between 1992 and 2006 nonfatal rates dropped from 8.9 to 4.4 injuries and illnesses per 100 workers, while the number of occupational fatalities due to injury declined from 6,217 to 5,703. These declines are largely not the result of compositional changes, as they are evident even within many industries, occupations, age, and gender categories. The declines are also mirrored in the data from other countries such as Canada, Finland, France, and others (Ussif 2004).

Research has been largely unable to explain these drops. Some commentators suggest that the declines might have resulted in part from technology (Ussif 2004), stronger economic incentives for safety, and legislative initiatives both brought about by higher workers' compensation costs (Conway and Svenson 1998; Boden and Ruser 2003), the deregulation of workers' compensation insurance (Barkume and Ruser 2001), and changes in Occupational Safety and Health Administration (OSHA) recordkeeping rules (Welch et al. 2007). Declines, particularly in nonfatal injury and illness rates, have continued up to 2006, suggesting that the trend will persist in the future. We acknowledge that our empirical analysis is focused solely on the impact of workforce composition changes and does not account for other largely unmeasurable factors that have contributed to workplace injury and illness declines. In a later section we do discuss some factors other than compositional changes that could affect workplace safety and health, such as the growth of contract and alternative forms of work, flexible work schedules and workplaces, and new workplace practices.

This chapter is organized as follows. The following section discusses the OSH data at the Bureau of Labor Statistics (BLS) in detail, followed by a brief discussion of other data utilized in the analysis. The next section provides a univariate analysis of injury and illness rates by industry, occupation, age, and gender. The following section builds upon this analysis by using 
a multivariate framework to examine the injury and illness data and then uses BLS projections data to predict future changes. Finally, a discussion of remaining issues and their impact on $\mathrm{OSH}$ outcomes and measurement is provided.

\subsection{Data}

The Bureau of Labor Statistics (BLS) conducts two data programs to track injuries, illnesses, and fatalities that occur in U.S. workplaces: the Survey of Occupational Injuries and Illnesses (SOII) and the Census of Fatal Occupational Injuries (CFOI). The SOII produces estimates of nonfatal injuries and illnesses that employers record on the Occupational Safety and Health Administration's (OSHA) "Log of Work-Related Injuries and Illnesses." The SOII annually collects employers' reports from about 176,000 private industry establishments and from state and local government establishments in some states. The survey excludes all work-related fatalities as well as nonfatal workplace injuries and illnesses to the selfemployed; to workers on farms with ten or fewer employees; to private household workers; and, nationally, to federal, state, and local government workers.

Injuries and illnesses logged by employers conform to definitions and recordkeeping guidelines set by OSHA. Nonfatal cases are recordable if they are occupational illnesses or if they are occupational injuries that involve lost worktime, medical treatment other than first aid, restriction of work or motion, loss of consciousness, or transfer to another job. Employers keep counts of injuries separate from illnesses and also identify for each whether a case involved any days away from work or days of job transfer or restricted work, or both, beyond the day of injury or onset of illness.

Summary information on the number of injuries and illnesses is copied by these employers directly from their recordkeeping logs to the survey questionnaire. The questionnaire also asks for the number of employee hours worked (needed in the calculation of incidence rates) as well as average employment (needed to verify the unit's employment-size class).

Besides injury and illness counts, survey respondents are asked to provide additional information for a subset of the most serious nonfatal cases logged, namely, those that involved at least one day away from work, beyond the day of injury or onset of illness. Employers answer several questions about these cases, including the demographics of the worker disabled, the nature of the disabling condition, and the event and source producing that condition. Most employers use information from supplementary recordkeeping forms and state workers' compensation claims to fill out the SOII's case form; some, however, attach those forms when their narratives answer questions on the case form. Also, to minimize the burden of larger employers, sampled establishments projected to have large numbers of cases involv- 
ing days away from work receive instructions on how to provide information only for a sample of those cases.

The Census of Fatal Occupational Injuries (CFOI) compiles a count of all fatal work injuries occurring in the United States in each calendar year. The program uses diverse state and federal data sources to identify, verify, and profile fatal work injuries. Information about each workplace fatality (industry, occupation, and worker characteristics; equipment being used; and circumstances of the event) is obtained by cross-referencing source documents, such as death certificates, workers' compensation records, and reports to federal and state agencies. This method assures counts are as complete and accurate as possible. For the 2005 data, over 20,000 unique source documents were reviewed as part of the data collection process. The scope of CFOI is broader than SOII, in that CFOI includes public sector workers and the self-employed.

Both the SOII and CFOI contain information about characteristics of the injury, illness, or fatality. This includes the nature of the case, which describes its physical characteristics, such as a sprain or a fracture. The event or exposure, which describes the manner in which the injury or illness was inflicted, is also captured. An event might be a fall or contact with equipment, for example. Also captured are the body part affected and the source of the injury or illness. All four of these characteristics are coded according to the BLS Occupational Injury and Illness Classification System (OIICS).

The SOII and CFOI provide estimates of the numbers of injuries, illnesses, and fatalities incurred by workers with various attributes, such as occupation, age, and gender. To better understand how the risk of workplace injury and illness varies among worker groups, it is helpful to control in some way for differences in the sizes of these groups. This is done in two ways in this chapter: by calculating injury, illness, and fatality rates and by including both injured and noninjured workers in logistic regressions. The injury and illness rates are simply the numbers of cases per standard unit of full-time-equivalent worker years (10,000 or 100,000 FTE in this chapter).

Neither the SOII nor the CFOI collects data on the number of workers or hours worked according to worker characteristics, such as occupation, age, or gender. ${ }^{1}$ As a result, it is not possible with these data alone to calculate injury and illness rates or to control for different-sized groups of workers. For this chapter, we rely on employment and hours worked estimates generated from the Current Population Survey (CPS). The CPS is a monthly survey of 60,000 households conducted by the Bureau of Census for the Bureau of Labor Statistics. It provides a comprehensive body of data on the labor force, employment, unemployment, and persons not in the labor force. The survey obtains information on the labor force status of each indi-

1. The SOII does collect hours worked for all workers in each sampled establishment. With this data element, it is possible to calculate injury and illness rates by state, industry, and establishment size. 
vidual age fifteen or older, including whether that person was employed in the preceding week, the class of the job (i.e., private wage and salary, selfemployed), the industry and occupation of the worker's job, and the actual hours worked. For one-fourth of the sample, actual hours worked is also obtained for a second job held by a worker.

In addition, the Annual Social and Economic (ASEC) Supplement to the Current Population Survey (CPS) is used for the multivariate analysis. The ASEC is a survey of 99,000 households conducted by the Bureau of Census for the Bureau of Labor Statistics. In addition to providing the usual CPS data, the ASEC provides additional information on work experience, income, noncash benefits, and migration.

Finally, BLS employment projections data are used to measure changes in labor force characteristics that are relevant to injury and fatality rates. The projections data cover the period 2004 to 2014 and provide employment numbers for gender by age categories, and detailed occupation and industry. The data are estimated by first projecting an aggregate level of labor supply and demand, and then determining industry and occupation distributions. Details of the methodology can be found in chapter 13 of the BLS Handbook of Methods (BLS 2009).

These projections are used to estimate how changing mixes of worker characteristics will affect future injury rates. The predicted change in employment numbers by gender/age, occupation, and industry at the level of detail used in the logistic regressions can be seen in figures 11.1, 11.2, and 11.3. The occupation and industry projections have been adjusted to match the universe of the SOII data as closely as possible. Public sector and agriculture employees were dropped from both the industry and occupation projections. In the industry projections, railroad workers were also excluded. ${ }^{2}$

\subsection{Univariate Description of Projections and Injury Data}

\subsubsection{Industry and Occupation Trends}

The BLS projections indicate that industry and occupation employment growth from 2004 to 2014 will tend to be in jobs that have lower risk of workplace injury and illness than the average job, so that the aggregate rate of workplace injuries and illnesses should tend to decline. However, there are some instances of high growth in high injury and illness sectors, most notably health care.

From 2004 to 2014, employment growth will tend to be focused in the service-providing sector, including education, health care and social assistance, and professional and business services. Employment is projected to

2. Although the projections data also has a separate category for wage and salary workers that would enable one to exclude the self-employed, there is not enough information available to exclude agriculture and the self-employed. 


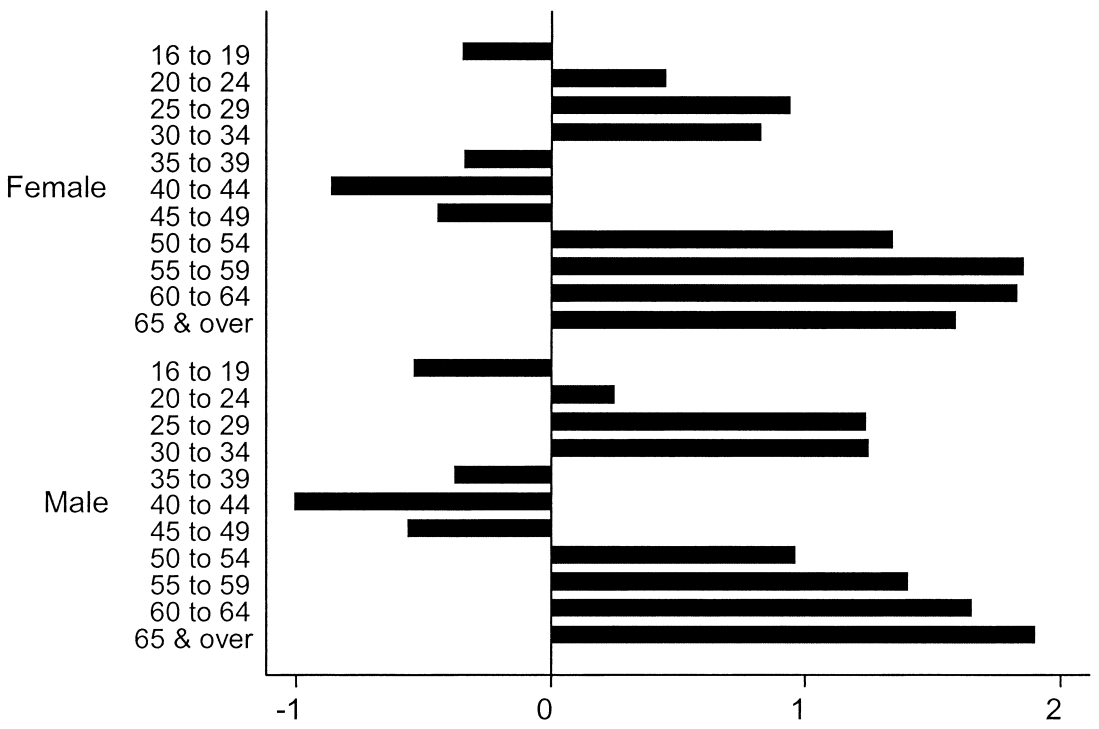

Fig. 11.1 Labor force growth, 2005-2014 (millions)

Architecture and Engineering Arts, Design, Entertainment, etc. Building and Maintenance Business and Financial Community and Social Services

Computer and Mathematical Construction Education

Farming, Fishing, Forestry Food Preparation and Serving Healthcare Healthcare Support Installation, Maintenance and Repair Legal Management Office and Administrative Personal Care Production Protective Service Sales Transportation

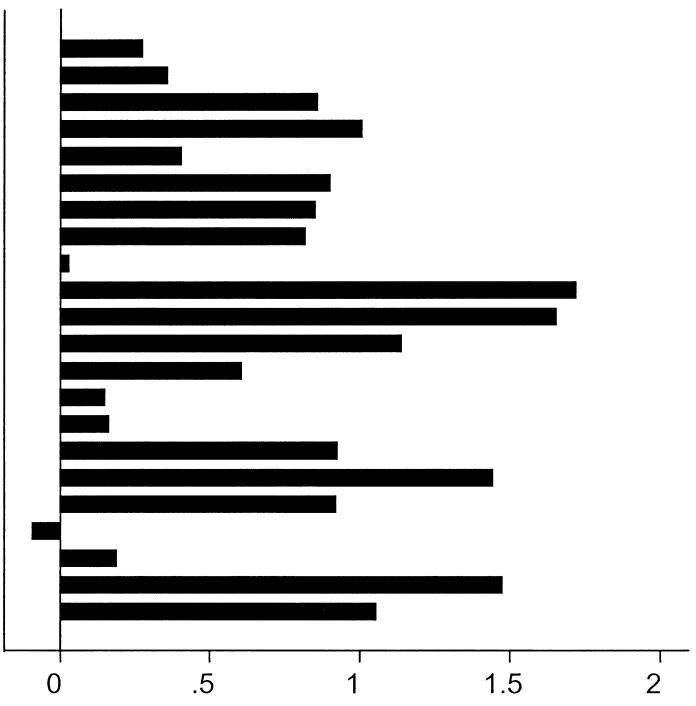

Fig. 11.2 Occupation growth, 2004-2014 (millions) 


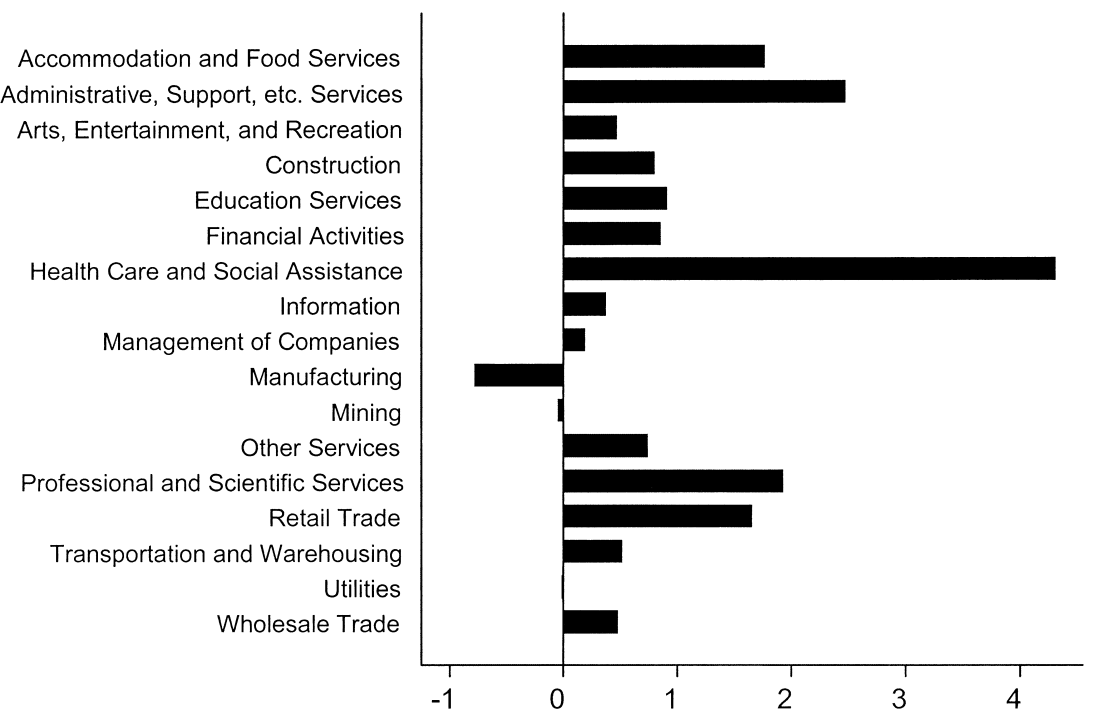

Fig. 11.3 Industry growth, 2004-2014 (millions)

grow 17 percent over the decade in the service-providing sector, while declining by a tenth of a percent in the goods-producing sector. This trend in general implies overall safer working conditions, as workplace injury and illness rates tend to be lower in the service-providing sector. In 2005, the rate of workplace injuries and illness in the private industry goods-producing sector was 6.2 per 100 full-time equivalent workers, while it was 4.1 in the service-providing sector.

Drilling down deeper, some of the fastest growing North American Industrial Classification System (NAICS) sectors also have relatively low workplace injury and illness rates, while some of the declining sectors have relatively high injury and illness rates. Educational services employment is projected to grow the fastest of any NAICS sector, at nearly 33 percent over the period from 2004 to 2014. This sector's private industry workplace injury and illness rate of 2.4 is about half the overall private sector rate of 4.6. In contrast, manufacturing, which accounts for 20 percent of workplace injuries and illnesses in private industry and an overall injury and illness rate of 6.3 ( 37 percent higher than the overall private industry rate), is projected to decline by over 5 percent from 2004 to 2014 .

However, there are some significant instances where relatively high-risk industries are also projected to have fast employment growth. This is particularly the case for the health care and social assistance sector, whose employment is projected to grow 30 percent over the decade, the second fastest of any sector. This sector's private sector injury and illness rate was 5.9 per 100 full-time equivalent workers, 28 percent higher than the overall 
private industry rate. Also noteworthy about this sector is that it tends to employ a large fraction of women, who sustain many of the industry's injuries and illnesses. In fact, in 2005, women sustained 80 percent of all injury and illness cases with days away from work in the private sector health care and social assistance sector, in comparison to 34 percent for all of private industry. The strong growth of this sector will imply that a growing fraction of women will be injured or become ill at the workplace.

The BLS's projections for occupational growth tend to have the same implications for safety and health as the industry projections. Many of the fast growing occupations will be relatively safe white-collar jobs, such as those in professional and related occupations, a large occupational group (20 percent of total employment) projected to grow 21 percent over the decade. However, growth will also be strong among service occupations, including building and grounds cleaning and maintenance and health care support occupations, some of which have higher injury and illness rates than the average job. In 2006, health care support occupations had the second highest rate of cases with days away from work among all occupational groups, at 279 per 10,000 workers or 2.2 times the rate for all workers. Building and grounds cleaning and maintenance occupations had the fourth highest rate of all occupational groups, at 244. Further, among occupations with at least 0.1 percent of employment, nursing aides, orderlies, and attendants had the highest rate of cases with days away from work, at 526 per 100,000 workers, or over four times the rate for all workers.

\subsubsection{Age/Gender}

Because the characteristics of workplace injuries, illnesses, and fatalities vary for workers of different age, the aging of the workforce has implications for the future composition of these workplace outcomes. The SOII and CFOI data, coupled with CPS hours worked estimates, show some clear differences by age.

Figure 11.4 shows that nonfatal injury and illness rates tend to decline with age for men, but that they remain relatively constant for women starting from the forty-five to fifty-four-year-old age category. Nonfatal rates drop about 8 percent for men between the forty-five- to fifty-four-year-old and fifty-five- to sixty-four-year-old age groups, and about 6 percent between the fifty-five to sixty-four and sixty-four + age groups. While some of this difference probably reflects differences in the jobs performed by older and prime-aged men, it is also likely that this finding persists after controlling for job mix. In contrast to men, the injury and illness rate profiles are relatively flat for women forty-five and older.

Results are strikingly different for fatalities. Figure 11.5 shows fatality rates for all workers by age category. This chart does not break out women separately, because women comprise only about 8 percent of all workplace fatalities and sustain few fatalities in the older age groups. The fatality rate 


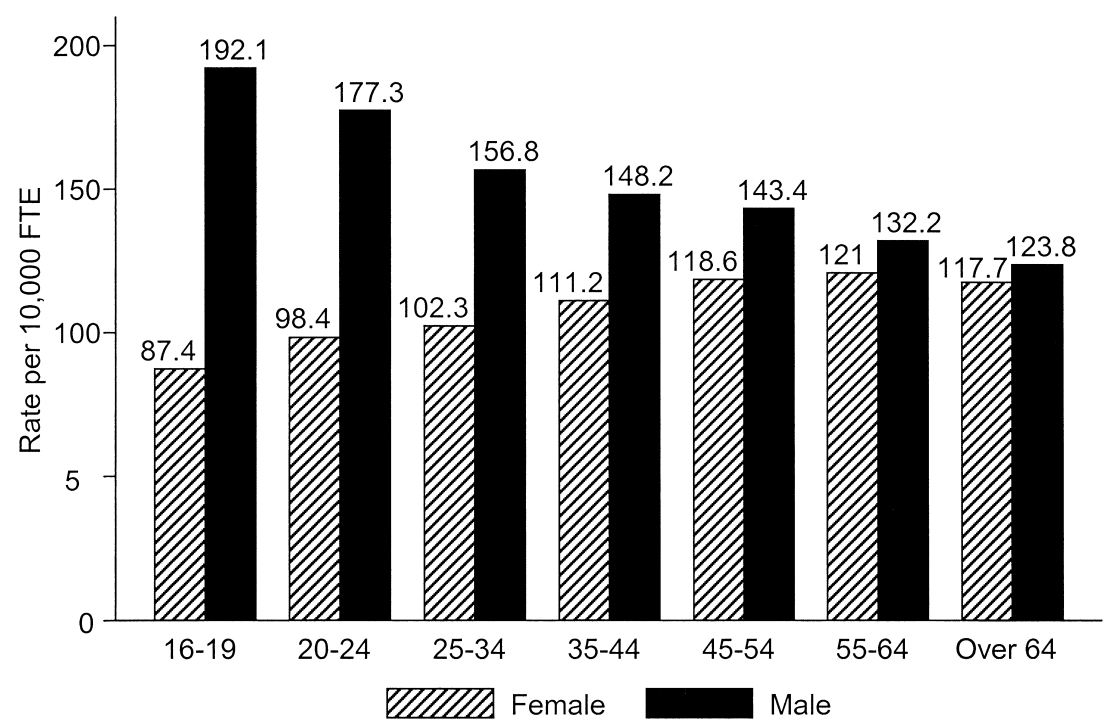

Fig. 11.4 Nonfatal occupational injury and illness rates, by age and gender, 2005

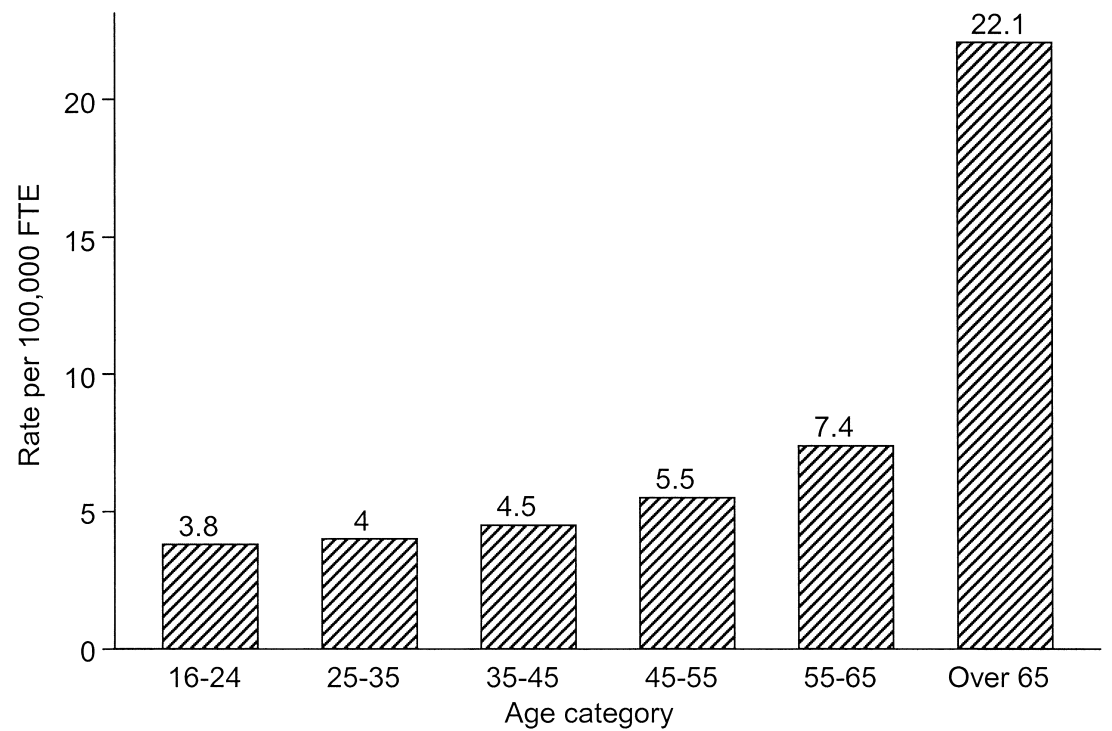

Fig. 11.5 Fatal occupational injury rates, 2005 
rises with age, from 4.5 fatalities per 100,000 workers for thirty-five- to forty-four-year-olds, to 5.5 for forty-five- to fifty-four-year-olds, and 22.1 for workers over sixty-four. This may reflect the fact that older (mainly male) workers are less likely to survive a severe workplace injury. Holding everything else constant, the sharp increase in fatality rates with age found in the data suggests that we would expect to see an increase in workplace deaths with the aging of the workforce.

Aging is also related to the types of nonfatal injuries and illnesses that occur. Table 11.1 shows how the natures of nonfatal cases with days away from work vary with age for men and women. For both genders, sprains and strains are by far the most frequent type of nonfatal case, overall about 41 percent of all cases in 2005. However, the percentage of cases accounted for by sprains shows an inverted U-shape with age for both men and women, peaking at the thirty-five- to forty-four-year-old age category for both groups. For men, sprains decline from about 43 percent to 30 percent between the thirty-five- to forty-four-year-old and over sixty-four-year-old age groups, while the decline is even more notable for women, from 48 to 32 percent.

The decline in sprains for older workers is in part made up by an increase in fractures. The percent of cases with days away from work accounted for by fractures tends to increase with age for both men and women, with a more noticeable increase for women. Whereas only about 4 percent of cases with days away from work are fractures for women age twenty-five to

Table 11.1 Distribution of occupational injuries and illnesses by nature, gender, and age, 2005

\begin{tabular}{|c|c|c|c|c|c|c|c|c|}
\hline & $\begin{array}{c}\text { All ages } \\
(\%)\end{array}$ & $\begin{array}{c}16 \text { to } 19 \\
(\%)\end{array}$ & $\begin{array}{c}20 \text { to } 24 \\
(\%)\end{array}$ & $\begin{array}{c}25 \text { to } 34 \\
(\%)\end{array}$ & $\begin{array}{c}35 \text { to } 44 \\
(\%)\end{array}$ & $\begin{array}{c}45 \text { to } 54 \\
(\%)\end{array}$ & $\begin{array}{c}55 \text { to } 64 \\
(\%)\end{array}$ & $\begin{array}{c}\text { Over } 64 \\
(\%)\end{array}$ \\
\hline \multicolumn{9}{|c|}{ Men } \\
\hline Total & 814,250 & 29,550 & 93,610 & 203,510 & 207,320 & 175,250 & 81,170 & 16,180 \\
\hline Total & 100.0 & 100.0 & 100.0 & 100.0 & 100.0 & 100.0 & 100.0 & 100.0 \\
\hline Sprains & 39.3 & 24.5 & 33.4 & 40.4 & 42.7 & 41.0 & 39.4 & 30.3 \\
\hline Bruises & 7.9 & 12.5 & 8.7 & 8.1 & 7.1 & 7.3 & 7.5 & 11.6 \\
\hline Cuts & 10.0 & 20.9 & 16.1 & 11.2 & 8.2 & 6.9 & 7.7 & 8.8 \\
\hline Fractures & 8.4 & 6.4 & 7.2 & 8.1 & 7.8 & 9.0 & 10.6 & 12.5 \\
\hline Pain & 7.6 & 5.3 & 6.8 & 6.9 & 8.2 & 8.2 & 8.8 & 7.2 \\
\hline All other & 26.7 & 30.5 & 27.8 & 25.3 & 26.1 & 27.6 & 26.0 & 29.7 \\
\hline \multicolumn{9}{|c|}{ Women } \\
\hline Total & 415,880 & 11,970 & 39,990 & 86,200 & 103,540 & 105,800 & 53,410 & 10,860 \\
\hline Total & 100.0 & 100.0 & 100.0 & 100.0 & 100.0 & 100.0 & 100.0 & 100.0 \\
\hline Sprains & 43.5 & 44.0 & 41.4 & 45.0 & 47.8 & 43.5 & 37.0 & 31.8 \\
\hline Bruises & 10.3 & 13.3 & 10.7 & 9.8 & 9.1 & 10.8 & 11.1 & 12.4 \\
\hline Cuts & 4.8 & 9.5 & 7.4 & 5.0 & 4.1 & 4.3 & 3.9 & 5.6 \\
\hline Fractures & 6.6 & 4.0 & 4.1 & 3.8 & 4.8 & 6.9 & 14.2 & 18.8 \\
\hline Pain & 9.3 & 7.9 & 9.4 & 10.7 & 9.2 & 8.7 & 9.0 & 1.7 \\
\hline All other & 25.5 & 21.2 & 27.0 & 25.7 & 25.0 & 25.9 & 24.7 & 29.7 \\
\hline
\end{tabular}


thirty-four, that percentage rises to 14 percent for women workers age fiftyfive to sixty-four and over 18 percent for women over age sixty-four. This result is consistent with the increasing incidence of osteoporosis in older women. However, the increase is also apparent for men. Fractures account for 8 percent of all cases with days away from work for men aged thirty-five to forty-four. That percentage increases to nearly 11 percent among males aged forty-five to fifty-four and 13 percent for men over sixty-four. In sum, the cross-sectional evidence for sprains and fractures suggests that, everything else equal, we expect that the aging workforce will lead to a decline in sprains and a growth in fractures as a percent of all cases with days away from work.

The SOII data provide information about the event that resulted in a nonfatal injury or illness. Table 11.2 shows that the most frequent event category overall is bodily reaction and exertion, which includes those events that lead to sprains and strains. Consistent with the declining importance of sprains and strains for older workers, bodily reaction and exertion becomes less important as an event leading to injury and illness for older workers. Instead, consistent with the age profiles for fractures, there is striking evidence of the growing importance of falls for older workers. For women age forty-five to fifty-four, 28 percent of injuries and illnesses resulted from falls. That percentage increases to 41.3 percent for women age fifty-five to sixty-four and 51.0 percent for women over sixty-four. Similarly, while falls account for 19.3 percent of events for men age forty-five to fifty-four, that percentage rises to 35.5 for men over sixty-four. These data suggest that the aging of the workforce will be accompanied by a growing frequency of fallrelated workplace injuries and illnesses.

The data on nonfatal injuries and illnesses display another age-related pattern. The median days away from work increases almost monotonically with age from only three days for the youngest group of workers to twelve for workers sixty-five years or older (figure 11.6). While the high median for older workers in part reflects a mix of injuries and illnesses weighted more heavily toward more severe categories, such as fractures, it is also the case that older workers remain out of work for longer periods of time for any given nature of injury or illness. For example, the median days away from work for a fracture for workers age twenty-five to thirty-four is twenty-one, while it increases to twenty-eight for workers fifty-five to sixty-four. Similarly, the median days away from work for a sprain is eleven for workers fifty-five to sixty-four, up from seven days for workers in the twenty-five to thirty-four age category. What is apparent is that either older workers suffer more severe injuries and illnesses or that they take longer to recover for an equivalent condition. This finding is consistent with the higher fatality rate for older workers.

In sum, the aging of the workforce is likely to be accompanied by an increase in the fraction of longer duration and more severe injury and illness 


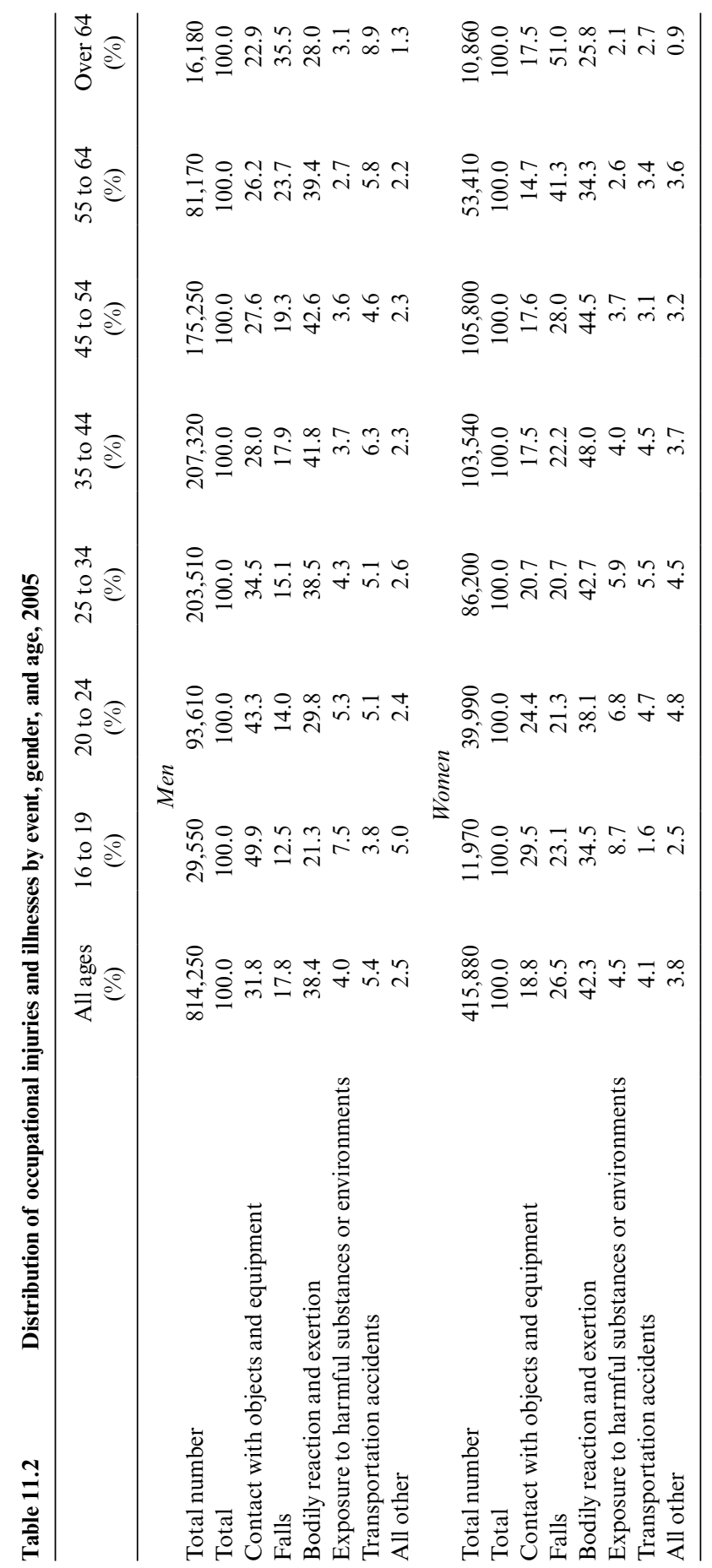




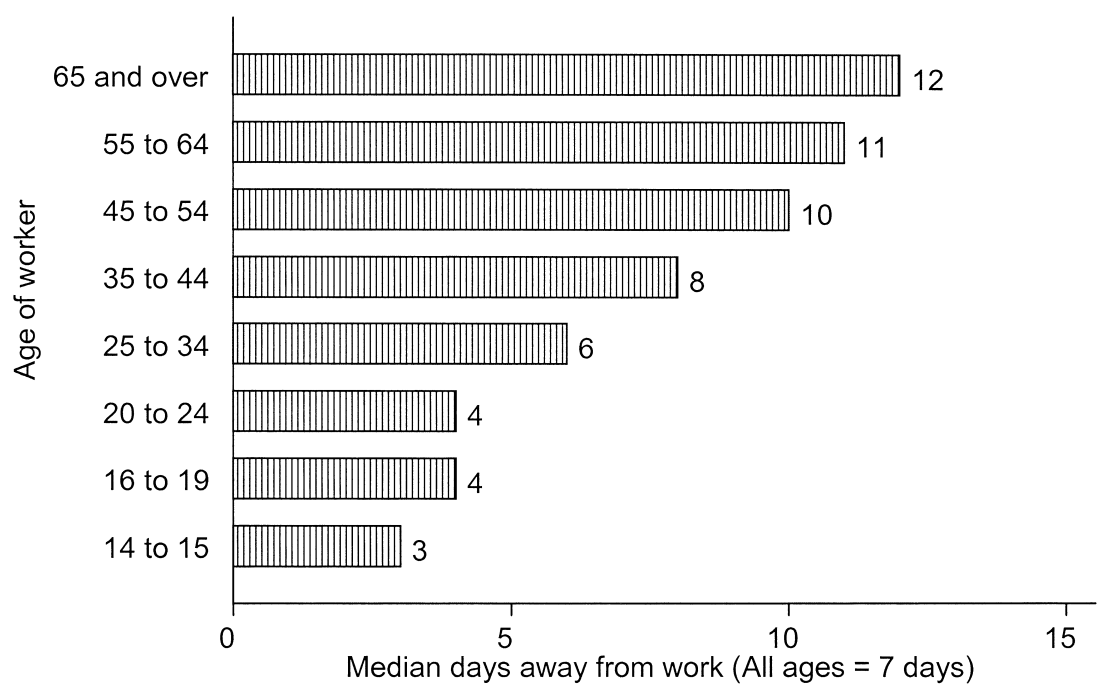

Fig. 11.6 Median days away from work due to nonfatal occupational injury or illness by age of worker, all United States, private industry, 2005

cases and by an increase in the rate of workplace death. These prognostications, of course, are based on cross-sectional comparisons that do not control for the different jobs that workers hold at different ages. A more rigorous multivariate analysis is pursued in the following section.

\subsection{Multivariate Analysis and Implications of Projections}

\subsubsection{Creation of Data Set for Analysis}

The multivariate analysis combines data from the SOII or CFOI with data from the CPS. By stacking these data sets, a universe of both injured and noninjured workers is obtained that contains information on age, gender, industry, and occupation of all workers combined with detailed information on worker injuries and illnesses or fatalities from the SOII and CFOI, respectively. The universe for the multivariate analysis for workplace injury and illness and for fatality projections was largely determined by the SOII data, namely no self-employed, private household workers, federal, state, nor local government workers. While the SOII does have information on employees of farms with greater than ten employees, all agriculture was excluded from the analysis as this restriction based on the number of employees at a farm could not be applied to the CPS data. Additionally, all employees of railroads were dropped from the analysis as information on gender is not available for this industry in the SOII data. From the CPS, all people over the age of sixteen who worked in the previous year for a private firm were included. To 
maintain comparability between the nonfatal and fatal analyses, the scope of the CFOI was restricted to be the same as that of SOII.

In order to create a data set incorporating the injury and illness data while maintaining the representativeness of the CPS, the weights need to be adjusted in the stacked data. There are many potential ways to adjust the stacked data to restore representativeness. The weighting scheme used here sums both the CPS and SOII weights for occupation by sex by age cells. ${ }^{3}$ The CPS observations are then down-weighted by the SOII total for a given cell. The following equations detail the methodology.

$$
\begin{aligned}
& W_{O, S}^{S O I I}=\sum_{O} \sum_{S} w_{O, S}^{S O I I} \quad \text { Total of SOII weights for occupation } O \text { and sex/age } S \\
& W_{O, S}^{C P S}=\sum_{O} \sum_{S} w_{O, S}^{C P S} \quad \text { Total of CPS weights for occupation } O \text { and sex/age } S \\
& w_{O, S}^{\text {new }}=w_{O, S}^{C P S}\left(1-\frac{W_{O, S}^{S O I}}{W_{O, S}^{C P S}}\right) \quad \begin{array}{l}
\text { New weight is down-weighted by SOII total for } \\
\text { that cell. }
\end{array}
\end{aligned}
$$

The occupation by sex by age cells are defined in the same way that they are for the regressions as described later.

Because the CFOI is a census, there are no weights. In the stacked CFOI/CPS data set, the CFOI observations are given a weight of 1 and the CPS observations are given their supplement weight. While in the stacked SOII/CPS data it was necessary to adjust the CPS weights to reflect the possibility that some CPS workers were injured, there is no overlap between the CPS and the fatalities data.

\subsubsection{Modeling}

In order to determine the impact that changes in the labor force have on injury, illness, and fatality numbers, a series of regressions were run on a set of employee characteristics common to the CPS, SOII, CFOI, and employment projections data. The characteristics of employees used to measure labor force changes are gender by age, occupation, and industry. There are twenty-two gender by age categories, twenty-two two-digit occupations, and sixteen major industries. ${ }^{4}$ The advantage to this multivariate approach is that

3. An earlier version of this chapter used an alternative weighting scheme in which workers in the CPS who received workers' compensation were dropped and weights on the SOII observations were adjusted so that they maintained their proportional value but summed to the value of the dropped CPS observations. The results using this weighting scheme are qualitatively very similar to the results shown later.

4. The gender by age categories are males sixteen to nineteen, twenty to twenty-four, twentyfive to twenty-nine, thirty to thirty-four, thirty-five to thirty-nine, forty to forty-four, forty-five to forty-nine, fifty to fifty-four, fifty-five to fifty-nine, sixty to sixty-four, and sixty-five and over, and the same for females. The occupation and industry categories roughly follow two-digit Standard Occupational Classification (SOC) and NAICS codes, respectively. The NAICS 55 was not included in the analysis as it is underrepresented when the Census Industry codes on the CPS are converted to NAICS codes. 
one can separately examine the impact of age, for example, while holding the industry and occupation mix constant. The multivariate approach would be impossible outside of the regression framework, as the gender by age by occupation by industry cells required in a tabular analysis would quickly become too thin for any meaningful analysis. As is shown following, results projecting the impact of age on the injury and illness numbers are much lower when controlling for industry and occupation than those that do not control for them.

The primary dependent variable of interest, worker injury, or illness, is a zero/one variable, therefore the regressions are estimated as logits. Beyond these top level equations, logistic regressions were also estimated by the most common natures and events causing injury or illness. These results highlight the fact that changing age, occupation, and industry mixes have different impacts on different types of work-related conditions. In order to get a sense of the impact of changing labor force characteristics on the severity of cases, the number of days away from work was also used as a dependent variable in an ordinary least squares regression. Finally, a logistic regression was estimated for fatalities.

Following the initial estimation, the marginal effect of each independent variable was calculated for each equation. The marginal effect was then multiplied by the change in the share of employees represented by that category measured using the projections data. These results are then multiplied by the total level of employment in 2004 and represent the estimated change in the number of injuries and illnesses given a change in the distribution of employment holding the total labor force fixed. While the labor force is expected to grow by 17 million over the time period in question, the results abstract away from overall growth in order to focus on distributional changes.

\subsubsection{Projections of Injury, Illness, and Fatality Changes}

Table 11.3 displays the marginal effects for a subset of the logistic regression results for nonfatal injuries and illnesses regressed on gender and age in the first column and gender, age, occupation, and industry in the second column. These results highlight the importance of controlling for the full set of covariates when examining the impact of gender and age on injury and illness statistics. In the first column, men appear more likely to receive workplace injuries or illness than women in all age categories. In the second column, the difference in the coefficients between men and women are much smaller. In fact, older women are more likely to receive workplace injuries and illnesses than older men. The difference between the two columns is likely due to the different occupations and industries in which men and women work. Men are more likely to receive workplace injuries and illnesses because they work in occupations and industries with higher injury and illness rates.

Using the marginal effects from the regression in column(2) and multiplying 
(1)

\begin{tabular}{|c|c|c|}
\hline \multicolumn{3}{|l|}{ Male } \\
\hline 16-19 & 0 & 0 \\
\hline \multirow[t]{2}{*}{$20-24$} & 0.0041 & 0.0022 \\
\hline & $(0.0008)^{* * *}$ & $(0.0000)^{* * *}$ \\
\hline \multirow[t]{2}{*}{$25-29$} & 0.0038 & 0.0028 \\
\hline & $(0.0007)^{* * *}$ & $(0.0000)^{* * *}$ \\
\hline \multirow[t]{2}{*}{$30-34$} & 0.0052 & 0.0039 \\
\hline & $(0.0008)^{* * *}$ & $(0.0000)^{* * *}$ \\
\hline \multirow[t]{2}{*}{$35-39$} & 0.0042 & 0.0032 \\
\hline & $(0.0007)^{* * *}$ & $(0.0000)^{* * *}$ \\
\hline \multirow[t]{2}{*}{$40-44$} & 0.0048 & 0.0034 \\
\hline & $(0.0008)^{* * *}$ & $(0.0000)^{* * *}$ \\
\hline \multirow[t]{2}{*}{$45-49$} & 0.0043 & 0.0034 \\
\hline & $(0.0008)^{* * *}$ & $(0.0000)^{* * *}$ \\
\hline \multirow[t]{2}{*}{$50-54$} & 0.0033 & 0.0028 \\
\hline & $(0.0007)^{* * *}$ & $(0.0000)^{* * *}$ \\
\hline \multirow[t]{2}{*}{$55-59$} & 0.0022 & 0.0022 \\
\hline & $(0.0007)^{* * *}$ & $(0.0000)^{* * *}$ \\
\hline \multirow[t]{2}{*}{$60-64$} & 0.001 & 0.0019 \\
\hline & $(0.0007)$ & $(0.0000)^{* * *}$ \\
\hline \multirow[t]{2}{*}{$65+$} & 0.0012 & 0.0011 \\
\hline & $(0.0008)$ & $(0.0000)^{* *}$ \\
\hline \multicolumn{3}{|l|}{ Female } \\
\hline \multirow{2}{*}{ 16-19 } & -0.0059 & -0.0024 \\
\hline & $(0.0003)^{* * *}$ & $(0.0000)^{* * *}$ \\
\hline \multirow[t]{2}{*}{$20-24$} & -0.0031 & 0.0002 \\
\hline & $(0.0004)^{* * *}$ & $(0.0000)^{* * *}$ \\
\hline \multirow[t]{2}{*}{$25-29$} & -0.0022 & 0.0017 \\
\hline & $(0.0005)^{* * *}$ & $(0.0000)^{* * *}$ \\
\hline \multirow[t]{2}{*}{$30-34$} & -0.0018 & 0.0023 \\
\hline & $(0.0005)^{* * *}$ & $(0.0000)^{* * *}$ \\
\hline \multirow[t]{2}{*}{$35-39$} & -0.0008 & 0.0033 \\
\hline & $(0.0005)$ & $(0.0000)^{* * *}$ \\
\hline \multirow[t]{2}{*}{$40-44$} & -0.0007 & 0.0031 \\
\hline & $(0.0005)$ & $(0.0000)^{* * *}$ \\
\hline \multirow[t]{2}{*}{$45-49$} & -0.0006 & 0.0033 \\
\hline & $(0.0006)$ & $(0.0000)^{* * *}$ \\
\hline \multirow[t]{2}{*}{$50-54$} & 0.0001 & 0.0042 \\
\hline & $(0.0006)$ & $(0.0000)^{* * *}$ \\
\hline \multirow[t]{2}{*}{$55-59$} & -0.0012 & 0.0026 \\
\hline & $(0.0005)^{* *}$ & $(0.0000)^{* * *}$ \\
\hline \multirow[t]{2}{*}{$60-64$} & -0.0013 & 0.0021 \\
\hline & $(0.0007)$ & $(0.0000)^{* * *}$ \\
\hline \multirow[t]{2}{*}{$65+$} & -0.0012 & 0.0026 \\
\hline & $(0.0007)$ & $(0.0008)^{* * *}$ \\
\hline Occupation & & Yes \\
\hline Industry & & Yes \\
\hline Observations & 260,121 & 260,121 \\
\hline
\end{tabular}

(2)

Note: Robust standard errors in parentheses. "Yes" in the table indicates that industry and occupation dummies were included in the regression.

*** Significant at the 1 percent level.

** Significant at the 5 percent level. 
by the change in the share of workers in each of the gender, age, occupation, and industry categories given from the employment projections data, we find that changes in the gender and age composition of the labor force lead to an estimated drop in the number of injuries and illnesses by about 2000 , holding the total labor force constant at the 2004 level. The estimated change due to occupation is a drop of 30,000 and the change due to industry is an increase of just over 100. The net total change is therefore a decrease of 32,000. This represents a small fraction of total employment but a larger fraction of injuries and illnesses, which numbered 1.2 million for this sample in 2005. Compared with the earlier univariate results, it is still true that older men are less likely to receive injuries and illnesses than their younger counterparts after age thirty. The multivariate results, however, show an increase in the probability of injury or illness for men between the ages of sixteen and thirty, whether or not one controls for occupation and industry. Differences between the univariate and regression results for younger workers are likely due to the lack of adjustment for hours in the regression analysis. An hours adjustment is not possible in the regression analysis due to the lack of information on the hours for injured or ill workers in the SOII.

While gender and age are important in predicting the probability of injury and illnesses, there are competing forces that cancel each other out leading to a small net change. Partially, this is due to an increase in both younger and older workers in the labor force. In addition, as is shown later, gender and age changes have different effects on different types of injuries and illnesses. The drop due to changes in occupations is due to a drop in the share of workers in production occupations - who have a high injury and illness rate - partially offset by a modest increase in the number of injuries and illnesses to health care support workers. Industry is not a powerful predictor of injury or illness. However, underlying the nearly zero net change is a modest increase in injuries and illnesses in the Health Care and Social Assistance industry, offset by small decreases in Manufacturing, Wholesale, and Retail trade.

The affect of the changing labor force varies when looking at different injury and illness types separately. Figure 11.7 shows the top seven nature of injury and illness categories plus an additional "all other" category to capture the remaining conditions. As can be seen in the figure, one categorysprains, strains, and tears - accounts for over 40 percent of all cases, followed by bruises, cuts, fractures, pain including back pain, illness, multiple injuries, and other. A logistic regression was run separately for each nature of injury or illness, the marginal effects calculated, and then the projections applied in order to compute the results shown in figure 11.8.

The changing gender and age makeup of the labor force has limited impact on the different natures except in sprains, where there is a large decrease, and fractures and multiple injuries, where there are large increases. The increase in fractures and multiple injuries is due to the predicted increase in the age of the labor force and particularly the increased share of the labor force rep- 


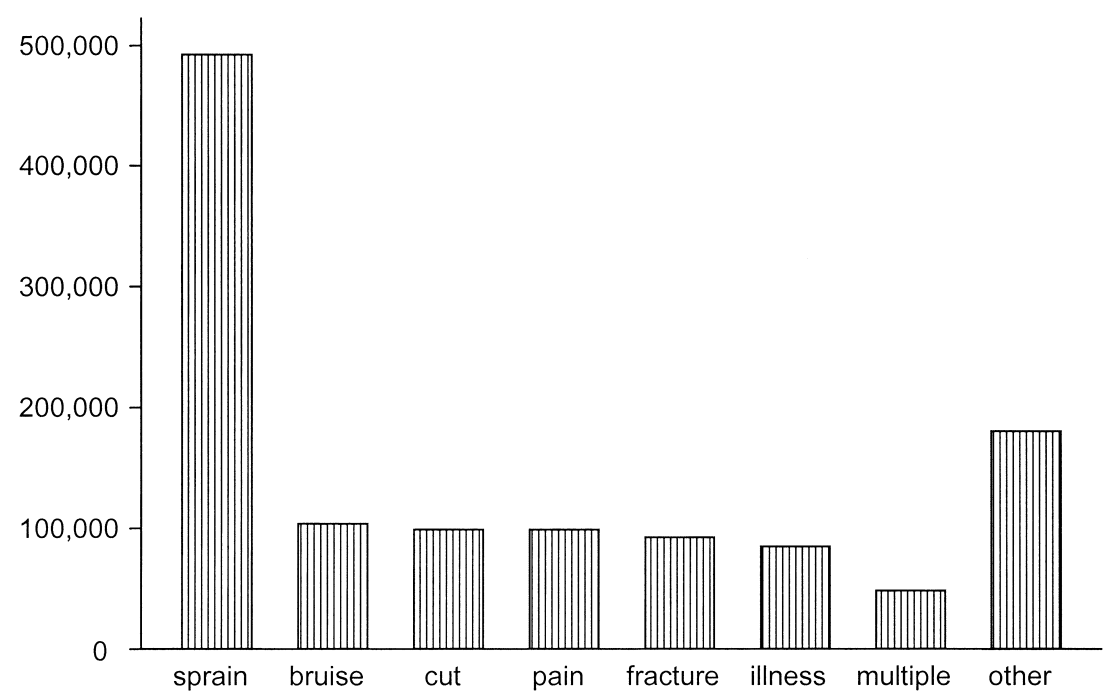

Fig. 11.7 Number of injuries by nature, 2005

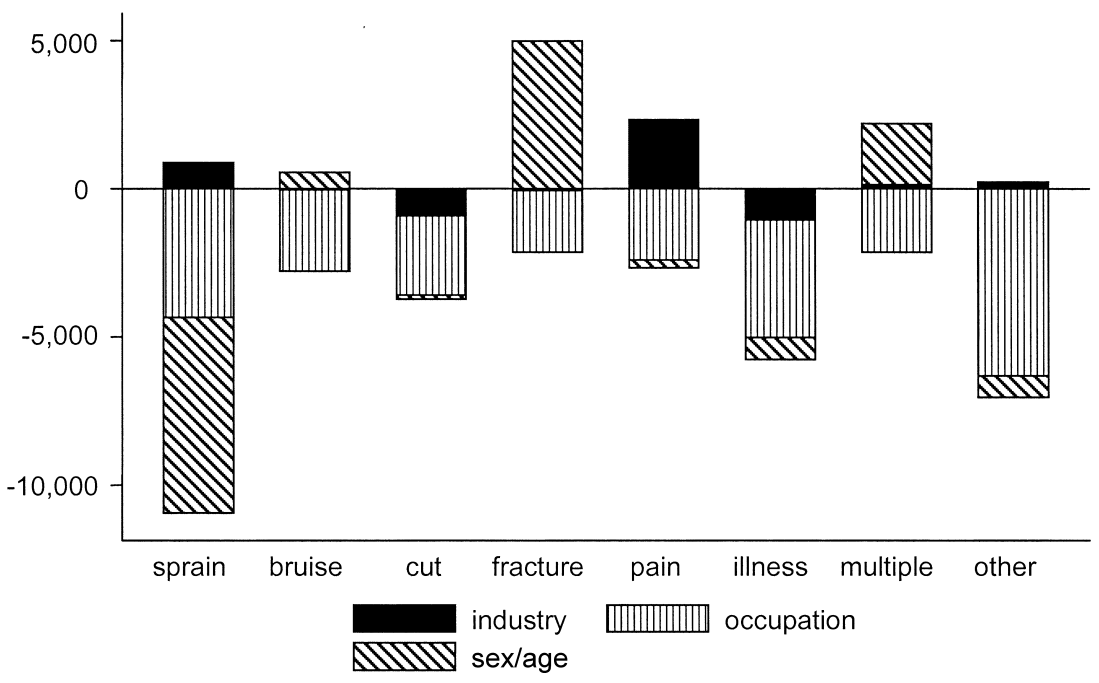

Fig. 11.8 Projected change in number of injuries, 2004-2014

resented by older women. Changes in the occupation distribution uniformly lead to lower numbers of injuries and illnesses regardless of the nature. The impact of the changes in industry is limited with an exception of the increase in the number of pain injuries, which is due to an increased share in the Health Care and Social Assistance industry. 
Age, gender, industry, and occupation changes also affect injury and illness rates differently depending on the event that caused the condition. Figure 11.9 shows the five most common events leading to injury and illness with an additional "all other" category capturing the remaining injuries. The distribution of events is less skewed than the nature of injury or illness distribution shown previously. Bodily reaction and exertion is the most common event, followed by contact with objects and equipment, falls, transportation accidents, and exposure to harmful substances or environments.

The results of applying the projections to the marginal effects estimated from a logistic regression on each of the event categories is displayed in figure 11.10. The decrease in cases resulting from bodily reaction and exertion is due to an almost equal drop in cases correlated with occupation and gender and age differences. The projected decrease in the share of production occupations explains the occupation component, while a fall in the share of middle-aged workers explains the drop in the sex and age component. Similarly, the fall in contact-related cases is also due to the drop in production occupations. The increase in cases resulting from falls is due primarily to the increase in the share of older women in the labor force, but also due to aging more generally. Age, gender, industry, and occupation are not strong predictors of cases due to exposure, transportation accidents, or other events.

While the previous calculations focus on determining the impact of the changing labor force on workplace injuries and illnesses by projecting changes in the number of cases, an alternative is to determine the impact on the number of days away from work. As mentioned earlier, older workers are associated with longer injury and illness durations. However, in the projec-

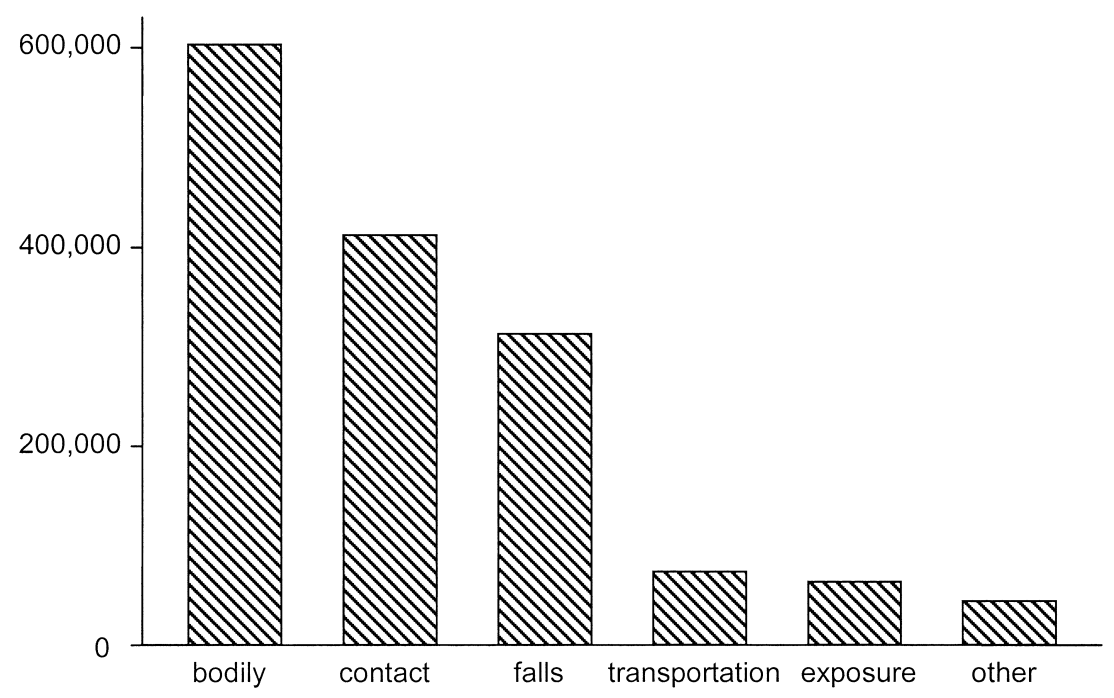

Fig. 11.9 Number of injuries, 2005 


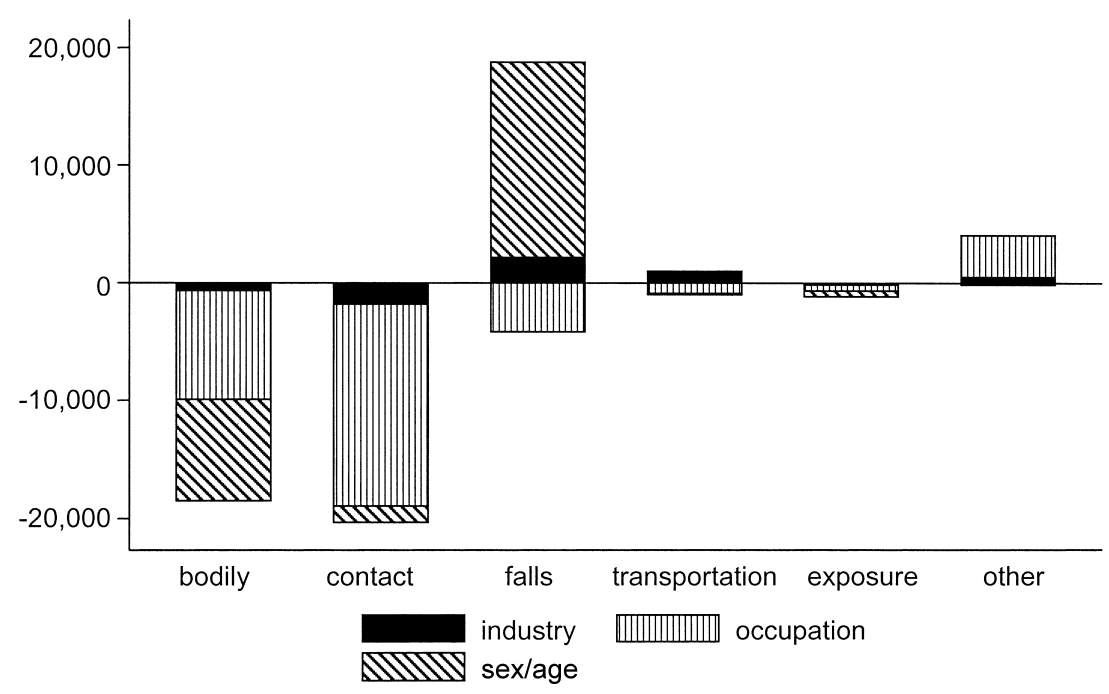

Fig. 11.10 Change in number of injuries by event, 2004-2014

tions data, while the share of older workers increases, the share of middleaged workers decreases. Both of these groups have higher than average durations, so the net increase in the number of days away from work due to gender and age changes is small at 0.3 days. While this projected change might seem small in light of the earlier figure 10.6 showing the median duration by age, these results additionally control for occupation and industry, further minimizing the role of age and gender. Occupation changes have little effect on the projected days away from work, with a decrease of .01 days. However, industry has more explanatory power, with a projected decrease in days away from work of 0.2 days.

A separate regression was run to determine the impact of changes in the labor force on workplace fatalities. As mentioned before, fatalities occur predominately among men, and more so among older workers. Due to the limited number of workplace fatalities among women, the age categories were not separated by gender. Table 11.4 reports the marginal effects from the logistic regression of fatalities on age in column (1) and fatalities on age, occupation, and industry in column (2). Including occupation and industry dummies mitigates the impact of age on fatalities, but only by a small amount.

After calculating the marginal effects and multiplying by the change in the share for each characteristic as given by the projections data, the net effect of labor force changes on workplace fatalities is a drop of seven fatalities on a base of 3,700 fatalities in the restricted scope 2005 data. Changes in the gender and age makeup of the labor force lead to a predicted increase of 
Logistic regression of fatalities on worker characteristics

\begin{tabular}{lll}
\hline & \multicolumn{1}{c}{$(1)$} & \multicolumn{1}{c}{$(2)$} \\
\hline $16-19$ & 0 & 0 \\
$20-24$ & 0.0000101 & 0.0000005 \\
& $(.00000)^{* *}$ & $(.00000)$ \\
$25-29$ & 0.0000186 & 0.0000028 \\
& $(.00001)^{* * *}$ & $(.00000)$ \\
$30-34$ & 0.0000222 & 0.0000039 \\
& $(.00001)^{* * *}$ & $(.00000)^{* *}$ \\
$35-39$ & 0.0000201 & 0.0000031 \\
& $(.00001)^{* * *}$ & $(.00000)$ \\
$40-44$ & 0.0000277 & 0.0000057 \\
& $(.00001)^{* * *}$ & $(.00000)^{* * *}$ \\
$45-49$ & 0.0000327 & 0.0000080 \\
& $(.00001)^{* * *}$ & $(.00000)^{* * *}$ \\
$50-54$ & 0.0000316 & 0.0000082 \\
& $(.00001)^{* * *}$ & $(.00000)^{* * *}$ \\
$55-59$ & 0.0000399 & 0.0000115 \\
& $(.00001)^{* * *}$ & $(.00000)^{* * *}$ \\
$60-64$ & 0.0000414 & 0.0000143 \\
& $(.00001)^{* * *}$ & $(.00000)^{* * *}$ \\
$65+$ & 0.0000556 & 0.0000175 \\
& $(.00001)^{* * *}$ & $(.00000)^{* * *}$ \\
Industry & & Yes \\
Occupation & & Yes \\
Observations & 84,492 & 84,492 \\
\hline
\end{tabular}

Note: Robust $z$ statistics in parentheses "Yes" in the table indicates that industry and occupation dummies were included in the regression.

$* * *$ Significant at the 1 percent level.

** Significant at the 5 percent level.

sixty-two fatalities, while occupation changes lead to a decrease of seventyfour fatalities and industry changes lead to an increase of five fatalities.

The fatality projections based on gender and age merit some comment. While fatality rates do rise steeply with age, the modest predicted increase of sixty-two fatalities with the aging of the workforce stems from an offset. There is an increase in the share of workers older than fifty, but there is also a decline in the share of workers age thirty-five to fifty. This latter decline leads to a drop in fatalities that offsets the increase in fatalities from the growth of the share of workers age fifty plus.

\subsection{Other Issues}

The preceding sections of this chapter have focused on the impact that changes in the age, gender, occupational, and industrial mix of the labor force may have on injury and illness statistics. The focus on these attri- 
butes of workers is in part due to the known relationships between these characteristics and the probability of injury and illness, but also because they are easily measurable in the SOII, CFOI, and complementary data sets that enable calculation of incidence rates. Beyond these basic worker characteristics, there are a host of other labor market trends that are likely to have an impact on workplace injuries, illnesses, and fatalities that are not easily measurable. A sampling of these trends, their likely impact on injury, illness, and fatality data, and the measurement issues involved are discussed later.

\subsubsection{The Growth of Contract and Alternative Forms of Work}

The Bureau of Labor Statistics projects that several industries providing contract workers will be among the fastest growing from 2004 to 2014. During that time period, BLS projects that the Employment Services industry will be the second largest source of employment growth in the economy, adding nearly 1.6 million jobs and rising to 5.1 million employees by 2014 (Berman 2005). This industry includes the Temporary Help Services and Professional Employer Organizations industries. ${ }^{5}$ The BLS also projects that the Facilities Support Services industry will be the sixth fastest growing industry, though the number of jobs added is only 54,000 .

These industries and others provide a wide variety of employees to the host businesses. Many of these employees are in relatively safe white-collar occupations. However, other workers provided from these industries perform hazardous work and their numbers are projected to grow. For instance, material-moving workers comprise over one-fifth of the Employment Services industry and that occupation is projected to add 236,000 jobs between 2004 and 2014. Labor and freight, stock, and material movers have a high rate of workplace injuries and illnesses at 3.6 times the rate for all private industry workers (USDL Release 07-1741, BLS 2007). Other contract workers work in hazard jobs such as cleaning the insides of petroleum containers.

Critics of the use of temporary and contract workers contend that they are being used in order for the host to circumvent the high costs (especially workers' compensation insurance) associated with certain forms of risky work. Further, they contend that temporary and contract workers may be at increased risk as they are less likely to recognize hazards or to be familiar with the temporary workplace (NIOSH 2002). Conversely, some contract workers may be particularly knowledgeable about the job risks that they face, as they perform specialized tasks frequently.

The growing use of contract and other forms of alternative labor creates

5. Establishments in the temporary help services industry supply workers to host businesses for limited periods of time. The temporary help workers remain employees of the temporary help establishments, though these establishments do not provide direct supervision. Employee leasing establishments, part of the professional employer organization industry, acquire and lease back employees of their clients and serve as the employer of the leased employees. 
problems both for workplace safety and health outcomes and surveillance owing to uncertainties about supervisory roles. Safety and health may be compromised to the extent that contract workers are supervised by the supplying company, whose supervisors are not familiar with the risks of a temporary work site. Job safety may be compromised even when workers are supervised by an employee of the host, as that supervisor may not be familiar with the skills of the temporary and contract workers under his or her supervision. However, as a report from the National Institute for Occupational Safety and Health notes (NIOSH 2002), empirical studies of the impact of contract and other forms of alternative work are scarce, so the impact of these new forms of work is not clear.

What is clearer is that the growth of contract work renders more difficult the task of measuring workplace safety and health. The two workplace safety and health programs of the Bureau of Labor Statistics treat contract workers somewhat differently. In either case, however, it is difficult to relate contract workers to the work sites where they work and, hence, to get a clear picture of the safety and health of these work sites.

The Survey of Occupational Injuries and Illnesses (SOII), which tracks nonfatal cases, obtains its information from logs and supplementary records that employers maintain according to regulations of the Occupational Safety and Health Administration (OSHA). The OSHA rules state that records for contract employees are to be maintained by the employer who supervises the employee, in many cases the contracting company. Specifically, regulations require a host employer to record an OSHA-recordable injury or illness of contract workers who are supervised on a day-to-day basis, even when such employees are not carried on the employer's payroll. The regulations spell out that day-to-day supervision occurs when "in addition to specifying the output, product, or result to be accomplished by the person's work, the employer supervises the details, means, methods and processes by which the work is to be accomplished" (29 CFR 1904.31 [Code of Federal Regulations (CFR)]).

In many cases, the host employer does not provide the supervision described in the regulations. Instead, that supervision is provided by the contracting company. In that case, data on contract employees do not provide information about the safety records of particular job sites. Instead, contracting industry data provide information about the safety records of all job sites and host industries at which the contractors work. In addition, contracting industry data provide information not only about contractors, but also about other employees of the contracting industry who are not contractors.

The issue of supervision may create some ambiguity about who has the recordkeeping role. While we have no empirical evidence, it is conceivable that some contractor injuries may go unrecorded on OSHA logs due to this ambiguity. 
The Survey of Occupational Injuries and Illnesses has another limitation when it comes to contract workers. The scope of SOII is limited to private industry and state and local government in some states. Among other groups, SOII excludes the self-employed. Many of these workers are contractors and thus, their safety experience is not captured in SOII.

The Census of Fatal Occupational Injuries (CFOI) approaches the collection of workplace fatality data in a different manner than SOII and also treats contractors differently. CFOI obtains information about workplace injury fatalities from multiple source documents, including death certificates, workers' compensation reports, OSHA fatality investigations, police reports, and even the press. The CFOI data compilers collate the information to rule out duplication and to identify unique fatalities that are work-related and due to traumatic occupational injury.

In CFOI, contract workers are reported as being in the industry that employs them. Typically, that means the industry of the company that actually pays that employee; that is, the contracting company. Therefore, it would be rare for a contract employee to be identified in the industry of the host company. Consequently, like the SOII, CFOI does not provide data about specific work sites or about the industry of the work sites where contract workers work. Instead, CFOI data for the contracting industries provide estimates of the job risk at all the work sites and industries where contractors in a particular contracting industry work.

The practice of assigning contracting employees to the employing industry has received attention from time to time. For example, the 2005 CFOI includes the fatalities from the British Petroleum (BP) refinery plant explosion in Texas City. The CFOI does not show these fatalities in the refining industry, but rather in the construction, engineering, and wholesale electrical equipment industries.

The practice of assigning decedents to the contracting industry does have the shortcoming of not providing site-specific fatality data. However, it does have the benefit of allowing the fatality counts to be aligned with employment data, which is based on employing industry. In this way, it is possible to calculate fatality rates.

It is important to note that, at the present time, CFOI does not identify whether or not a particular decedent was a contract worker. In some cases, it may be able to determine this from the source documents. For example, OSHA fatality investigation reports will identify contractors. However, many workplace fatalities are not identified from OSHA fatality reports and the other source documents may not provide the needed information to determine whether a particular worker is a contract worker. It may be that the best way to study the issue of contract worker fatalities is by means of a specific follow-back of fatality cases that focuses on whether or not the worker was a contract worker.

Unlike SOII, the scope of CFOI does include the self-employed. Thus, 
CFOI will include the deaths of those self-employed workers who are contractors.

\subsubsection{Alternative Workplaces and Flexiplace}

Access to technology complementary to telework has increased dramatically since the 1990s, while at the same time the costs of both the equipment and communications have fallen. These factors have enabled a greater number of workers to telework due to both the increased communications access and the number of jobs suitable for telework. The BLS data show that the number of workers who usually did some work from home as part of their primary job increased through the 1990s, from 19.9 million in 1991 to 21.4 million in 1997. However, this number has since leveled off, with 20.7 million workers doing work from home in 2004, the most recent data available. While the overall numbers of telecommuters may not yet reflect these changes in the underlying economy, the number of potential telecommuters has undoubtedly increased.

Like alternative employment relationships, teleworking and alternative workplaces weaken employer monitoring of the OSH environment, potentially increasing injuries and illnesses. Alternative workplaces may also increase the challenge of properly measuring both injuries and illnesses and worker exposure to risk. According to OSHA rules (Directive number OSHA Instruction CPL 2-0.125, Home-Based Worksites). OSHA will not conduct inspections of employees' home offices nor will they hold employers liable for employees' home offices. However, employers who are required to keep OSHA logs are required to keep records of injuries and illnesses that occur in a home office.

\subsubsection{Alternative Work Schedules, Long and Intermittent Shifts, Flexitime}

Alternative work schedules, including shift work and compressed work schedules, result in work at irregular times, more intermittency of work, and longer periods of work. All of these may affect work rhythms and fatigue, increasing injuries. Night work may be associated with riskier working environments, due to poor lighting and crime. Research on the impact of work hours on the probability of injury consistently find that the hour of work matters. Pergamit (2005) uses the National Longitudinal Survey of Youth (NLSY) to run logistic regressions of injury on a series of dummies describing a worker's schedule, including the shift and hours worked. $\mathrm{He}$ finds that workers who work nonday shifts have a 22 to 27 percent higher likelihood of injury. ${ }^{6}$ Forston (2004), using Texas Worker's Compensation and a different approach, finds that inherent features of night work that

6. Nonday shifts include evening shifts, night shifts, rotating and split shifts, and irregular work schedules. 
cannot be explained by age, occupation, industry, or fatigue lead to higher injury rates.

The percentage of workers with flexible worker hours has been increasing from the mid-1980s, while the percentage of workers working nonday shifts has been decreasing. ${ }^{7}$ Both of these changes are likely closely related to changes in the mix of occupations and industries prevalent in the labor market. Professional services are more likely to offer flexible schedules and have become a larger part of the labor market. Conversely, the mining and manufacturing industries are more likely to have night shifts and are shrinking industries. However, there are also labor market trends working in the opposite direction. Health care workers are more likely to have alternative shifts than other workers and are a growing part of the labor market. While shifts in industry and occupation shares may explain the changes in the proportion of the labor force working different work schedules, research has shown that the higher rate of injury in nonday shifts cannot be explained by industry and occupation alone. That is, there are factors inherent in nonday shifts that increase workplace injury and illness risk.

Further research on the impact of different shifts may be possible, as the BLS Survey of Occupational Injuries and Illnesses now captures information about the day and time of injury or illness and the hours on the shift before onset. These data may be combined with information from the American Time Use Survey.

\subsubsection{New Workplace Practices}

The past two decades have witnessed the adoption of a variety of new workplace practices that involve quality and process management initiatives. These initiatives have been given a variety of names, such as high performance and high involvement work systems, flexible workplaces, total quality management, and lean production. They involve a number of practices, including shifting decision making downward to teams of workers, job rotation, process simplification to eliminate wasted time and motion, just-in-time methods, and a continuing emphasis on quality (NIOSH 2002).

In principle, involving workers in decision making and focusing on process should have beneficial effects on worker safety and health. Workers can identify sources of job risk and work to reduce or eliminate these. Further, job rotation can be used to change the tasks of workers suffering from repeated trauma disorders. Critics, however, contend that quality and process initiatives reduce worker autonomy and control and that the productivity gains obtained through the initiatives come from a speedup and intensification of work. These critics also contend that job rotation moves workers to new tasks for which they are not well trained. The result is worsened worker safety and health, particularly in the form of increased 
incidence of cumulative trauma disorders and stress (Brenner, Fairris, and Ruser 2004).

Initial research on this topic was in the form of case studies largely in the automotive industry. Among the limited cross-industry empirical work, Fairris and Brenner (2001) match industry-level measures of cumulative trauma disorders (CTDs) from SOII to a separate survey of workplace practices conducted by Osterman. They find the use of quality circles (but no other workplace practice) was positively associated with CTDs.

Research by Brenner, Fairris, and Ruser (2004) extends the work of Fairris and Brenner using establishment-level data on workplace transformations (e.g., quality circles, work teams, and just-in-time production) matched to measures of cumulative trauma disorders (CTDs) at the same establishments. The data on workplace transformations was obtained from the 1993 Survey of Employer Provided Training, while the data on CTDS came from the 1993 Survey of Occupational Injuries and Illnesses. The research found that just-in-time approaches to production and quality circles are both positively and statistically significantly associated with rates of cumulative trauma disorders across establishments. Further, the quantitative impact on CTDs of these two workplace practices was sizeable, ranging from 20 to 65 percent of the mean CTD rate, depending on sample and estimating specification.

Finally, related interesting work by Askenazy and Caroli (2006) uses data for French workers. They find that the use of quality norms and job rotation is associated with greater mental strain and more occupational injuries; though, while the probability of a "benign" injury is 25 to 40 percent higher for workers involved in these two practices, the effect on serious injuries is never statistically significant. Further, the impact of "regular collective discussion on work organization" seems to be associated with higher occupational risks. Askenazy and Caroli hypothesize that this positive relationship may stem from endogeneity-discussions are more likely when there are more safety problems. They do note, however, that their results suggest that these discussions do not result in a safer workplace.

The evidence presented previously suggests that new workplace practices may result in more occupational injuries, CTDs, and job stress. However, it must be noted that the body of literature on this topic is not extensive. Indeed, the National Institute for Occupation Safety and Health (NIOSH) states that additional research is needed to determine whether these workplace practices have a beneficial or detrimental impact of worker safety and health. The NIOSH further notes that since "these work systems are seldom implemented in a standardized fashion, their effects on worker safety and health may depend on their specific characteristics and the implementation process" (NIOSH 2002, 10). Further study will also require better measurement of the incidence of these workplace practices, as the United States has only an ad hoc series of surveys that lack common definitions (Handel and Levine 2006), and these surveys are now somewhat dated. 


\subsection{Conclusions}

Using existing workplace safety and health data and BLS projections, we are able to assess the impact of certain labor market trends on workplace safety and health. Specifically, we are able to assess the impact of changes from 2004 to 2014 in the labor force distributions by age, gender, industry, and occupation.

The analysis suggests that labor force shifts between 2004 and 2014 will have perceptible impacts on the frequency and distribution of workplace injuries and illnesses. Aging of the workforce (and gender shifts) will result in an increase in more severe injuries, such as fractures and fatalities, while falls will become a more frequent event associated with workplace injury. The median duration of an injury or illness will also rise slightly. Decreases in the number of production workers will likely lead to decreases in the number of injured and ill. However, the growing number of jobs in health care will work to increase the number of injured and ill, particularly among women.

The data generally do not permit us to estimate the impact of other important labor force trends, such as the growth in contract labor, alternative forms of work, alternative workplaces and hours, and new workplaces. However, the literature provides hypothetical effects and sometimes empirical evidence that we have summarized in the chapter. In general, the effect of these various trends on workplace safety and health is ambiguous, though the cited literature seems to suggest that new workplace practices (such as just-in-time inventories, quality circles, and possibly job rotation) are associated with more job stress, cumulative trauma disorders, and occupational injuries.

Beyond impacting workplace safety and health outcomes, emerging labor market trends also affect the ability to monitor workplace safety and health. One important area is the growing use of contract labor. The current BLS occupational safety and health surveillance systems for nonfatal workplace injuries and illnesses and for fatal workplace injuries do not permit the estimation of injury, illness, and fatality rates according to the location of work performed. Thus, with these surveillance systems, we are not able to measure the job risks at the work sites of employers hosting contract workers. Monitoring and measuring safety and health also becomes more difficult as more work is performed at alternative work sites, such as at home.

\section{References}

Askenazy, P., and E. Caroli. 2006. Innovative work practices, information technologies and working conditions: Evidence for France. IZA Discussion Paper no. 2321, September. 
Barkume, A., and J. Ruser. 2001. Deregulating property-casualty insurance pricing: The case of workers' compensation. Journal of Law and Economics 44 (1): 37-63.

Berman, J. M. 2005. Industry output and employment projections to 2014. Monthly Labor Review 128 (November): 45-69.

Boden, L. I., and J. W. Ruser. 2003. Workers' compensation "reforms," choice of medical care provider, and reported workplace injuries. Review of Economics and Statistics 85 (4): 923-29.

Brenner, M. D., D. Fairris, and J. Ruser. 2004. Flexible work practices and occupational safety and health: Exploring the relationship between cumulative trauma disorders and workplace transformation. Industrial Relations 43 (1): 242-66.

Conway, H., and J. Svenson. 1998. Occupational injury and illness rates, 1992-96: Why they fell. Monthly Labor Review 121 (11): 36-58.

Fairris, D., and M. Brenner. 2001. Workplace transformation and the rise in cumulative trauma disorders: Is there a connection? Journal of Labor Research 22 (January): $15-28$.

Fortson, K. 2004. The diurnal pattern of on-the-job injuries. Monthly Labor Review 127:18-25.

Handel, M. J., and D. I. Levine. 2006. The effects of new work practices on workers. UC Berkeley: Institute for Research on Labor and Employment. Working Paper no. 131-06.

National Institute for Occupational Safety and Health (NIOSH). 2002. The changing organization of work and the safety and health of working people. NIOSH document no. 2002-116, April.

Pergamit, M. R. 2002. Work schedules and work injuries. Paper presented at the Joint Meeting of the Society of Labor Economists and European Association of Labour Economists. June, San Francisco.

U.S. Bureau of Labor Statistics. 2007. Nonfatal occupational injuries and illnesses requiring days away from work, 2006. News Release USDL 07-1741, November 8.

. 2009. Handbook of methods. Washington, DC: United States Department of Labor.

Ussif, A. 2004. An international analysis of workplace injuries. Monthly Labor Review 127 (3): 41-51.

Welch, L. S., X. Dong, F. Carre, and K. Ringen. 2007. Is the apparent decrease in injury and illness rates in construction the result of changes in reporting? International Journal of Occupational and Environmental Health 13 (1): 39-45.

\section{Comment Jeff E. Biddle}

Nestoriak and Ruser have written a useful chapter. There are changes coming in the nature of the labor force and its activities about which we can be fairly certain, and it is worth thinking about how those changes will influence the number and types of workplace injuries that will occur. For example, we know the workforce will be aging; Nestoriak and Ruser alert us to the fact that as a result of this we should be prepared for fewer injuries due to

Jeff E. Biddle is professor of economics at Michigan State University. 